\title{
Reconstruyendo las representaciones del delincuente en Criminalogía Moderna (Buenos Aires, 1898-1901) : raza, inmigración y delito
}

Reconstruire les représentations du délinquant dans Criminalogía Moderna

(Buenos Aires, 1898-1901) : race, immigraton et crime

Reconstructing the representations of the offender in Criminalogía Moderna

(Buenos Aires, 1898-1901): race, immigration and crime

\section{Federico Luis Abiuso}

\section{CpenEdition}

\section{Journals}

Edición electrónica

URL: http://journals.openedition.org/rhj/2783

DOI: $10.4000 /$ rhj.2783

ISSN: 0719-4153

Editor

ACTO Editores Ltda

\section{Referencia electrónica}

Federico Luis Abiuso, «Reconstruyendo las representaciones del delincuente en Criminalogía Moderna

(Buenos Aires, 1898-1901) : raza, inmigración y delito », Revista Historia y Justicia [En línea], 13 | 2019,

Publicado el 20 noviembre 2019, consultado el 25 mayo 2020. URL : http://journals.openedition.org/ rhj/2783; DOI : https://doi.org/10.4000/rhj.2783

Este documento fue generado automáticamente el 25 mayo 2020

Revista Historia y Justicia 


\section{Reconstruyendo las} representaciones del delincuente en Criminalogía Moderna (Buenos Aires, 1898-1901) : raza, inmigración y delito

Reconstruire les représentations du délinquant dans Criminalogía Moderna

(Buenos Aires, 1898-1901) : race, immigraton et crime

Reconstructing the representations of the offender in Criminalogía Moderna

(Buenos Aires, 1898-1901): race, immigration and crime

Federico Luis Abiuso

\section{NOTA DEL EDITOR}

Recibido: 21 de mayo de 2019 / Aceptado: 07 de octubre de 2019

\section{Introducción}

1 En el marco de uno de los cursos dictados en el Collège de France, y más particularmente en la clase fechada el día 21 de marzo de 1979, Michel Foucault señala un punto de inflexión fundamental en la historia de los pensamientos criminológicos: el deslizamiento, acaecido a lo largo del siglo XIX, del homo penalis hacia el homo criminalis $^{1}$. Profundizando en tal aspecto, Pasquale Pasquino afirma que este último se constituye como objeto-personaje privilegiado de un saber especializado (la criminología), cuya génesis el autor sitúa hacia fines del siglo XIX ${ }^{2}$. Cuestionados los pilares de libre albedrio, racionalidad y responsabilidad, y con énfasis en la defensa 
social y la etiología del delito, el homo criminalis es definido como un "ser diverso" respecto del resto de la población.

En ese contexto fundacional, la criminología nace ligada a la influencia del positivismo, lo cual implica como rasgo fundamental una cuestión de método: el estudio científico del delincuente a partir de las causas que determinarían su comportamiento criminal. De tal manera, dependiendo de cuáles eran los factores que se priorizaban (biológicos, antropológicos, psicológicos, sociales, psicopatológicos), uno de los tópicos más discutidos y controvertidos de la criminología en su vertiente positivista giró en torno a la clasificación de los delincuentes. Pudiéndose mencionar, al respecto, aquellos tipos de delincuentes descriptos por Cesare Lombroso y Enrico Ferri, autores centrales de la Escuela Positiva italiana: delincuentes natos, criminaloides (o delincuentes habituales), locos delincuentes, delincuentes pasionales y delincuentes ocasionales, o igualmente definidos por Lombroso como pseudo-delincuentes ${ }^{3}$. Desde Argentina, José Ingenieros propuso una clasificación alternativa con respecto a las recién mencionadas, distinguiendo -a partir de sus rasgos psicopatológicos- a delincuentes natos o locos morales, delincuentes habituales o pervertidos morales, delincuentes de ocasión, delincuentes por locuras constitucionales o adquiridas, delincuentes epilépticos, delincuentes alcoholistas y delincuentes estéticos ${ }^{4}$.

De hecho, tal clasificación había sido anticipada -como primera ocasión- en Criminalogía Moderna $a^{5}$, publicación periódica dirigida por Pietro Gori, editada entre 1898 y 1901 desde Buenos Aires, y la cual fue caracterizada a posteriori como "la primera revista criminológica argentina" ${ }^{\mathrm{y}}$ "la primera revista argentina que se propone [...] el 'estudio científico' del delincuente y la difusión del positivismo criminológico en el país”.

4 Del heterogéneo y variopinto conjunto de representaciones sobre el delincuente difundidas en aquella publicación -uno de cuyos tantos ejemplos podría ser la criminalidad femenina ${ }^{8}{ }^{-}$, mi interés de investigación radica en describir los modos en que allí eran tematizados los vínculos entre inmigración, raza y delito. Me pregunto, a su vez, por los saberes que, fueren expertos o profanos -provenientes de autores vernáculos o de otras regiones geográficas-, eran convocados a sustentar aquellos vínculos 9 .

5 Considero que este constituye un camino posible para describir discursos criminológicos sobre la presunta mayor tendencia a la comisión de delitos de un "otro" diferente a un "nosotros". Más concretamente, mi propuesta es la de efectuar una lectura de Criminalogia Moderna en clave del peso atribuido a la raza y a la condición inmigrante como factores criminógenos; o en palabras de Marta Monclús Masó, "analizar el rol que tiene la 'raza', la etnia o la condición de inmigrante o extranjero en la producción de criminalidad" ${ }^{10}$. Este recorrido puede brindarnos herramientas para componer prejuicios y estereotipos sobre la imagen del delincuente del pasado.

6 Desde otra dirección, el presente artículo constituye un aporte para continuar indagando, en base a aquellos autores que se orientaron a temáticas afines, en uno de los numerosos capítulos de la historia de la criminología positivista en Argentina: los modos en que eran definidos -en el contexto de la inmigración masiva- los vínculos entre inmigración (en ese entonces, mayoritariamente europea) y delincuencia.

7 En términos del abordaje teórico-metodológico, me centré específicamente en una estrategia cualitativa de investigación en particular, la Teoría Fundamentada, 
desarrollada pioneramente por Barney Glaser y Anselm Strauss en la década de 1960, con el propósito de aportar procedimientos acerca de cómo promover la generación de teoría a partir de los datos. Al respecto, doy a conocer las categorías (así como sus propiedades) que devinieron centrales tras haber aplicado los procedimientos del método de comparación constante -a la vez que recuperando los tipos de codificación descriptos por Anselm Strauss y Juliet Corbin- en el dominio empírico de Criminalogía Moderna. Comprendiendo, ante todo, que se trata de uno de los caminos posibles para dar cuenta de las representaciones del delincuente allí difundidas.

En cuanto a la estructura del artículo, en el próximo apartado detallo aspectos centrales de la metodología seleccionada, y a continuación reseño aquellos autores que -en su carácter de antecedentes de la temática abordada- considero pertinente aquí recuperar. Antes de incursionar en el terreno de las categorías que, en torno a los vínculos entre inmigración, raza y delincuencia, devinieron centrales en el análisis realizado, presento una caracterización de la revista en cuestión.

\section{Estrategia teórico-metodológica}

Del conjunto de aspectos de la Teoría Fundamentada que fueron puntualizados por Glaser y Strauss, me interesa retomar tres de ellos: relevancia teórica, método de comparación constante e investigación de biblioteca.

Respecto al primero, se trata de uno de los criterios del muestreo teórico, el cual guio la selección de aquellos artículos editados en Criminalogía Moderna donde se hacía referencia, en mayor o en menor medida, o de manera más o menos explícita, a los nexos entre raza, inmigración y delito.

11 En cuanto al método de comparación constante, es definido -en una primera instanciacomo la combinación de procedimientos de codificación y análisis para la generación de teoría, siendo sistematizada a partir de la producción de los datos. Una caracterización posterior es realizada a partir de los rasgos que distinguen al método de comparación constante de otra de las aproximaciones al análisis cualitativo que presentan los autores, la inducción analítica. Al respecto, Glaser y Strauss señalan que el método de comparación constante no se ocupa como meta principal de testar provisionalmente teoría, sino de generar, respecto a los problemas que se investigan, categorías conceptuales, propiedades e hipótesis ${ }^{11}$.

Desglosado en sus distintas fases o etapas, el método de comparación constante involucra (1) la comparación de incidentes (observaciones, fragmentos de entrevistas, documentos, etc.) aplicables a cada categoría, (2) la integración de las categorías y sus propiedades, (3) la delimitación de la teoría y (4) la escritura de la teoría. Veamos en qué consiste cada una de ellas.

13 En la primera, el investigador comienza por comparar entre sí la información obtenida y codificar cada incidente en sus datos dentro de tantas categorías como sea posible, sea que surjan categorías nuevas o que encajen en las ya existentes ${ }^{12}$. Retomando una de las elaboraciones posteriores de la Teoría Fundamentada -los tipos de codificación conceptualizados por Anselm Strauss y Juliet Corbin-, Miguel Valles refiere en esta etapa a la codificación abierta: la búsqueda activa y sistemática de categorías y sus propiedades $^{13}$. 

integración de estos dos elementos que componen la teoría. Al respecto, Glaser y Strauss destacan centralmente dos actividades: la comparación entre incidentes y el análisis intenso hecho alrededor de una categoría (codificación axial), en términos de sus propiedades y de las relaciones que se podrían establecer con otras categorías. segunda, a las operaciones analíticas de integración de los elementos de la teoría (categorías, propiedades e hipótesis), la tercera alude a la delimitación de la teoría. Uno de los criterios en que la misma se desglosa es el de parsimonia -hacer máxima la explicación y compresión de un fenómeno con el mínimo de conceptos y formulaciones-, el cual se vuelve operativo en el método de comparación constante mediante la búsqueda deliberada y sistemática de categorías centrales, en torno a la cual otras se puedan agrupar e integrar. Al respecto, y retomando nuevamente a Strauss y Corbin, Valles incorpora en esta etapa la codificación selectiva.

Finalmente, la última de las fases refiere a la escritura de la teoría; en este punto el investigador cuenta con los datos codificados, los memos y una teoría.

En el caso específico del presente artículo, mi propósito no fue el de generar teoría, sino que la apropiación que hice de las herramientas provistas por Glaser y Strauss estuvo orientada a la producción y análisis de categorías y sus propiedades, en tanto uno de los caminos posibles para reconstruir las representaciones acerca de las relaciones entre raza, inmigración y delincuencia. De tal manera, apliqué los procedimientos del método de comparación constante -recuperando asimismo los distintos tipos de codificación (abierta, axial y selectiva) conceptualizados por Strauss y Corbin- al dominio empírico constituido por Criminalogía Moderna. Consultar este material, y trabajarlo, a su vez, desde la Teoría Fundamentada nos sitúa en el tercero de los aspectos que fueron mencionados al iniciar el apartado, la investigación de biblioteca.

En décadas recientes, algunos de los procedimientos y lineamientos relativos a cómo promover Teoría Fundamentada (método de comparación constante, muestreo teórico, codificación, sólo para referir a algunos), han sido retomados por distintos autores. Ya sea para dar cuenta de la aplicación de esta estrategia de investigación sobre diversos objetos de estudio, o para describir, en el ámbito de un manual o libro dedicado a la metodología de la investigación social, cuáles serían sus principales aspectos, existe una tendencia -al menos en la disciplina sociológica-, de otorgar una primacía a la técnica de la entrevista como única fuente de elaboración teórica. De tal modo, es pasada por alto una característica, a mi juicio, medular: la Teoría Fundamentada constituye una estrategia que puede ser aplicada a cualquier tipo de información cualitativa (entrevistas, documentos, artículos, libros, etc.) en un mismo estudio. Este aspecto resulta más llamativo aún al reconocer que Glaser y Strauss dedican íntegramente un capítulo a destacar el uso de diversas fuentes cualitativas en la generación de teoría sociológica ${ }^{14}$.

19 En este sentido, y teniendo en cuenta que este artículo se ubica en un punto de intersección entre la estrategia de la Teoría Fundamentada y la indagación de materiales consultados en el ámbito de una biblioteca, otro de los objetivos que me propongo abordar es el de retomar los aspectos de la investigación de biblioteca, tal como a ellos hicieron referencia los autores. Considero que este retorno puede contribuir, desde una reflexión teórico-metodológica, a destacar las posibilidades y potencialidades de aplicación de la Teoría Fundamentada, escapando del unilateralismo 
de la técnica de entrevista y apuntando, en cambio, a una multiplicidad y diversidad de fuentes. Asimismo, favorecería el establecimiento de puentes y diálogo entre distintas disciplinas y campos de saber, a partir de los trabajos hechos sobre las mismas fuentes o similares.

Como puntapié inicial, Glaser y Strauss destacan que los materiales con los cuales trabajamos en la biblioteca son potencialmente valiosos para generar teoría mediante el análisis comparativo (más específicamente, a través del método de comparación constante), tanto como otras técnicas cualitativas de investigación social, tales como la observación y la entrevista.

21 A continuación, los autores señalan algunos de los elementos en común que existen entre la investigación de biblioteca y la técnica de entrevista. Son mencionados, entre otros, los siguientes. Es posible indagar en la opinión de determinados expertos a partir de una entrevista o igualmente consultando una revista especializada en particular. Es en este sentido que indagué en Criminalogía Moderna, al concebirla como una publicación periódica especializada en el ámbito criminológico, y más concretamente, ligado a su matriz positivista. La táctica del trabajo de campo de asistir a reuniones clave tiene su táctica análoga en la investigación de biblioteca, especialmente cuando queremos encontrar en el mismo espacio y lugar a personas representativas de diferentes posiciones sociales. Esto es particularmente relevante cuando podemos encontrar, en una misma revista y acerca de temáticas de diversa índole, el punto de vista de autores de variadas trayectorias y regiones geográficas. Tanto durante la realización de entrevistas como en la indagación de materiales de biblioteca, el investigador encuentra el uso reiterado de diversas palabras clave por parte de los sujetos que están siendo estudiados; las cuales son, con frecuencia, reconstruidas analíticamente como etiquetas, y puestas en relación posteriormente con sus distintas propiedades.

Otra de las contribuciones asociadas a la investigación de biblioteca es la accesibilidad, pues las fuentes disponibles de ser consultadas aportan materiales y recursos valiosos acerca del pasado; tal como fue señalado con anterioridad, la revista objeto de este artículo fue editada entre los años 1898 y 1901. Además, el investigador que trabaja con fuentes recopiladas en el catálogo y archivo bibliotecario puede volver sobre ellas la cantidad de veces que considere necesarias; en este punto, el momento de salida del campo se vuelve más difuso que al utilizar otras técnicas de producción de datos, tales como la entrevista y la observación. Otra característica mencionada acerca del trabajo con fuentes consultadas en el ámbito de la biblioteca apunta a la dimensión temporal: estos materiales están dispuestos frecuentemente de manera cronológica, y la profundidad histórica de los mismos es comparativamente superior a los datos producidos por medio de observaciones o entrevistas.

23 Si bien Glaser y Strauss mencionan que estos serían algunos de los aportes de la investigación de biblioteca, es preciso afirmar que la elección de los materiales empíricos con los cuales vamos a trabajar en nuestra investigación no depende exclusivamente de alguno de ellos en particular, sino también de decisiones teóricometodológicas relacionadas a la definición de nuestros objetivos y preguntasproblemas, que nos orientarán en el camino de la producción y análisis de datos.

24 Por todo aquello que fue anteriormente expuesto, considero que uno de los puntos más fuertes de la Teoría Fundamentada consiste en su posibilidad de ser aplicada a diversas fuentes en un mismo estudio, siempre teniendo presente la comparabilidad entre ellas. 
Al poderse incorporar así distintos dominios empíricos en la misma investigación, apropiarnos de dicha estrategia hace posible acercar a distintas disciplinas y campos de saber entre sí, abriendo las condiciones de posibilidad de entrecruzamientos y del establecimiento de puentes entre unas y otras. Esta interdisciplinariedad constituye sin duda un aspecto que, a mi juicio, tiende a enriquecer el campo de los estudios sociohistóricos acerca de la cuestión criminal, y más específicamente, el capítulo destinado a la historia de los discursos criminológicos sobre el "otro", al dotarlo de más herramientas y profundidad cronológica en las discusiones sobre el presente ${ }^{15}$. En este sentido, concibo este artículo como una escena dialógica con autores que se orientaron a temáticas similares a las que aquí propongo -o al menos, conexos a ellas-, algunos de los cuales serán reseñados a continuación.

\section{Antecedentes de la temática}

Históricamente, Argentina ha sido un país fuertemente vinculado a diversas dinámicas y flujos migratorios. Una de ellas tuvo su génesis sobre todo a partir de la segunda mitad del siglo XIX, y fue posteriormente fomentada por las elites políticas dirigentes, mediante la ley de Inmigración y Colonización de 1876 (o también denominada "Ley Avellaneda"), para atraer inmigración europea, con el objeto de modernizar al país y modificar sustancialmente la composición de la población residente. Dada la intensidad y el volumen de la inmigración, así como por el papel que cumplió en la modernización de la estructura social, Gino Germani define a esta dinámica como una inmigración masiva $^{16}$, la cual tuvo como principales protagonistas mayoritariamente a italianos y españoles, y en menor medida, a polacos, rusos, franceses y alemanes. A partir de la información censal, Germani reconstruye, en otro de sus textos ${ }^{17}$, un panorama general del peso cuantitativo que tuvo la población extranjera entre los años 1869 y 1947. Así, en $1869,210.300$ personas eran de origen extranjero, cifra que se eleva en 1895 a 1.004.500, y en 1914 a 2.358.000, casi una tercera parte de la población total del país. Apoyándose igualmente en datos censales, Fernando Devoto destaca que "la inmigración europea y la historia de la Argentina, desde sus mismos comienzos como Estado independiente y aun antes de ellos, están indisolublemente ligadas" ${ }^{18}$. Desde un punto de vista similar, Gabriel Anitua afirma que "la Argentina de entonces se construía bajo el proceso inmigratorio"19.

Por su parte, siguiendo lo expuesto por Lila Caimari, la mayoría de los recién llegados se queda en las ciudades, entre las cuales ninguna atrae a tantos como Buenos Aires: pasa de tener 187 mil habitantes en 1869 a más de un millón y medio en 1914, constituyendo los extranjeros la mitad de la población ${ }^{20}$.

Así, en un contexto de política de puertas abiertas (marcado por el aumento demográfico, la expansión urbana, las oportunidades económicas y las transformaciones acaecidas en el mercado de trabajo), se promovieron distintas zonas de contacto entre nativos y migrantes, las cuales involucraron la implementación de diversas estrategias de relación por parte del Estado, así como la producción -desde la mirada de la sociedad receptora- de identidades y alteridades.

Como bien lo señala Eduardo Domenech, si bien la inmigración europea fue concebida, en un primer momento, como solución a los distintos problemas sociales de la época (una condición para poblar el "desierto", impulsando progreso, modernización y "civilización" en el país), será pronto pensada por las propias elites dirigentes como 
problema, o bien, asociada a problemas ${ }^{21}$. De tal forma, aquellos inmigrantes calificados como "indeseables" eran construidos -desde la visión del Estado- como una amenaza al orden público y a la seguridad nacional; ya sea que se trate de militantes anarquistas o de delincuentes viajeros, se instrumentaron distintos mecanismos para hacerles frente, entre ellos la expulsión (promulgada y respaldada en la Ley de Residencia de 1902) y las iniciativas de cooperación policial en materia de intercambios de información ${ }^{22}$.

Del conjunto de problemas a los cuales pasó a estar asociada la inmigración (el desorden urbano, la introducción de "ideologías extrañas al ser nacional" ${ }^{23}$, la integración o cohesión social), uno de ellos era el delito -o al menos, la potencial conducta delictiva o presunta mayor criminalidad del inmigrante con respecto al nativo-, que marcaba asimismo su incorporación a las "clases peligrosas" ${ }^{24}$. En este sentido, y de acuerdo a su afinidad temática con los intereses de investigación que dieron lugar a este artículo, querría retomar aquellos autores que, desde una perspectiva historiográfica, se han orientado a indagar los modos en que la criminología positivista -en tanto saber consagrado académicamente y en cuanto ocupaba un importante lugar institucional-estatal al interior de la sociedad receptoradefinió y conceptualizó, en el contexto de los siglos XIX y XX y con eje en el ámbito de la Ciudad de Buenos Aires, los nexos entre inmigración europea y delincuencia.

Al respecto, Ricardo Salvatore destaca que, en tanto sistema interpretativo de la cuestión social, los criminólogos positivistas construyeron distintos imaginarios en torno a aquello que percibían como amenazas para el orden social, siendo una de ellas las tendencias criminales de los inmigrantes ${ }^{25}$. Ilustrativamente, menciona a Luis María Drago y su libro, Los hombres de presa (1888), así como refiere a la figura de Cornelio Moyano Gacitúa, quien reunió en La delincuencia argentina ante algunas cifras y teorías (1905), algunas estadísticas delictivas para mostrar que el influjo de los inmigrantes europeos, más que proveer de civilización y una mayor productividad laboral, trajo en cambio crecientes tasas de delito. En un texto posterior ${ }^{26}$, señala que, dadas las características de un mercado de trabajo cambiante e inestable, los criminólogos positivistas definían una conexión directa entre cambios ocupacionales y delincuencia; más aún, se les adjudicaba una pretendida falta de ética de trabajo a los inmigrantes, lo cual los alejaba del mundo del trabajo y los acercaba al mundo del delito.

Orientándose en la misma dirección, Eugenia Scarzanella reconstruye distintas representaciones acerca del vínculo inmigración-delito ${ }^{27}$. El cual no sólo se hizo presente en la literatura y en ensayos, sino también en la identificación de un nexo científico entre uno y otro; punto en el cual la autora introduce la figura de Moyano Gacitúa. De la misma manera, refiere a otros modelos de equivalencia entre inmigración y delito: la existencia de una colonia criminal de "lunfardos", delincuentes profesionales que se dedicaban al robo, a la estafa y a la venta de billetes falsos, grupos e individuos extranjeros dedicados al crimen político (subversivos, anarquistas) y un conjunto de estigmas acerca de la predisposición biológica y racial al delito, englobados en la definición de la "delincuencia de sangre", característica del contingente de "latinos".

Por su parte, Lila Caimari señala que el tema del delincuente extranjero singularizó los estudios nacionales de criminología argentina ${ }^{28}$. Son mencionados al respecto Los hombres de presa de Luis María Drago (1888) y Causas del delito (1892) de Antonio Dellepiane. Más aún, la autora subraya que esta asociación delito-inmigración pasó a 
constituir un fundamento del sentido común criminológico de especialistas y funcionarios.

Este último argumento podría ser problematizado a partir de la descripción que proporciona Máximo Sozzo acerca de cuáles evidencias se construyeron acerca del nexo inmigración-delincuencia y cuáles fueron los argumentos que se plantearon para otorgarle sentido al mismo ${ }^{29}$. Situando el eje en los viajes culturales que atravesaron los discursos de la cuestión criminal, el autor describe distintos momentos o etapas de importación de la criminología positivista en Argentina, sobre todo, en la Ciudad de Buenos Aires. Lejos de pensar el proceso de traducción de un contexto a otro como mera translación, transposición o traspaso de las ideas, es concebido como más complejo, y el cual involucra una dimensión creativa e innovadora ${ }^{30}$.

De hecho, y de manera pertinente con respecto al tópico del presente artículo, Sozzo sostiene:

Una de las metamorfosis que experimentó la criminología positivista en su importación al contexto argentino pasó por la manera en que sus traductores locales introdujeron en sus propios textos unas visiones acerca del potencial vínculo entre inmigración y crimen, explorando un tema que no había resultado medular en el discurso criminológico europeo, pero que iría adquiriendo en este escenario peculiar una cierta importancia ${ }^{31}$.

Así, en un primer momento, la cuestión del antedicho nexo no recibió un tratamiento muy detallado, pero en algunos casos aparece un incipiente reconocimiento de su carácter problemático: en un folleto publicado en 1888 por Norberto Piñero, en la tesis de Cuneo Antola sobre el tema de la prevención del delito, Francisco Ramos Mejía toma partido alrededor de este vínculo para enfatizar la necesidad de reformar la legislación penal y Eduardo Coronado se orienta en la misma dirección recurriendo - al igual que los anteriores autores mencionados-, a uno de los soportes clave del vínculo causal entre inmigración y criminalidad: las estadísticas que la Policía de la Capital comenzó a elaborar y recopilar en los albores de la década de 1880. El punto de vista de Antonio Dellepiane, que de alguna manera hace de transición entre el primero y el segundo momento de la traducción cultural de la criminología positivista, es retomado por Sozzo para demostrar que, en su tesis Las causas del delito, pone en cuestión ese nexo causal entre la inmigración y el delito.

Al emprender el recorrido por el segundo momento, es destacada, en continuidad con otros autores, la figura intelectual de Cornelio Moyano Gacitúa. Para él, la inmigración en tanto factor de criminalidad está asociada a la composición racial, a las características de los grupos nacionales que mayoritariamente llegaron a Argentina, italianos y españoles. Hay en este autor, por ende, una racialización del nexo entre inmigración y delito. Otro de los autores descriptos por Sozzo en este segundo momento es Miguel Lancelotti. Si bien este último destaca la influencia de la inmigración en el aumento de la criminalidad en la Ciudad de Buenos Aires, advierte la necesidad de evitar las exageraciones al respecto, al discutir la validez del porcentaje de los delincuentes extranjeros detenidos por la policía respecto al porcentaje total de la población. Pero incluso es interesante destacar que no niega en términos absolutos la existencia de un nexo causal.

En su conjunto, las incursiones realizadas por Salvatore, Scarzanella, Caimari y Sozzo ${ }^{32}$ acerca de la historia de los discursos sobre la cuestión criminal, y más particularmente, de los modos en que la criminología positivista definió los nexos entre inmigración (en 
ese entonces, mayoritariamente, europea) y delincuencia no sólo constituyen un antecedente ineludible en cuanto a su afinidad temática con mis intereses de investigación, sino también una inspiración en su carácter de promotores de preguntas e interrogantes en torno a la presencia o ausencia de esas representaciones, tipologías e imaginarios en Criminalogía Moderna, publicación objeto de este artículo y acerca de la cual presento sus rasgos más salientes en el siguiente apartado.

\section{Abriendo el telón: la revista y sus características}

Con el objetivo de proveer observaciones vivas sobre el fenómeno de la criminalidad, en relación con las diversas causas que la determinan y a la profilaxis contra el delito, se inaugura, hacia noviembre de 1898, la publicación de Criminalogía Moderna. La misma se enmarca en un contexto más amplio de introducción de la criminología en su matriz positivista -y en un diálogo no exclusivo ni exento de críticas con exponentes de la Scuola Positiva tales como Cesare Lombroso, Enrico Ferri, Raffaele Garofalo, entre otrosen ámbitos académicos, espacios institucionales y en el plano de diversas publicaciones periódicas a través de las cuales eran difundidas las ideas y nociones asociadas a esta corriente de pensamiento.

En tal sentido podemos mencionar la creación, en el marco de la Universidad de Buenos Aires, de una cátedra exclusivamente dedicada al derecho criminal en 1887 (la cual adoptó como programa la enseñanza de los exponentes mencionados anteriormente ${ }^{33}$ ), así como la inserción de autores positivistas en cátedras universitarias, uno de cuyos ejemplos puede considerarse la labor de Francisco de Veyga ${ }^{34}$.

- En cuanto a los espacios institucionales, me resulta relevante señalar la fundación de la Sociedad de Antropología Jurídica (1888), la cual contó con la participación de profesionales destacados del campo de la medicina y el derecho. La inauguración del Servicio de Observación de Alienados (1900), posteriormente denominado Clínica Psiquiátrica y Criminológica de la Policía de la Capital, ubicado al interior del Depósito de Contraventores "24 de Noviembre". Y la creación, en 1907, del Instituto de Criminología -organizado dentro de la Penitenciaría Nacional-, a partir de la iniciativa de Antonio Ballvé y José Ingenieros.

41 Respecto al plano de las publicaciones periódicas a través de las cuales eran difundidas las ideas y nociones de la criminología positivista, Hernán Olaeta sostiene:

Una de las características más llamativa de la fuerte instalación de los discursos criminológicos en el país fue la amplia divulgación que tuvieron estas ideas en muchos ámbitos. Uno de ellos fue el de las numerosas publicaciones provenientes del sector académico, el policial, e incluso el periodístico ${ }^{35}$.

Una de estas publicaciones -uno de los canales de difusión del positivismo criminológico en Argentina, al decir de Creazzo- fue Criminalogía Moderna. Al respecto, Julia Rodriguez destaca un detalle del título que se vincula, en gran parte, con su contenido: el uso intencional, por parte de los editores, del término criminalogía, con el objeto de reflejar el énfasis de que se trataba de una ciencia del criminal más que del crimen $^{36}$.

43 Tal como fue mencionado anteriormente, Criminalogía Moderna (en adelante, CM) fue dirigida por Pietro Gori, abogado y anarquista de origen italiano, quien arribó a Buenos Aires el 21 de junio de 1898 en calidad de exiliado y haciéndose pasar por un turista inglés. En un interesante texto sobre la estadía de Gori en Argentina, en términos de sus 
aportes y vicisitudes, Martín Albornoz lo destaca como una figura clave tanto en el campo de la política (a partir de la militancia anarquista en el movimiento obrero), como en la cultura científica porteña de fin de siglo, siendo definida la fundación de la publicación como uno de sus más notables proyectos culturales en el país ${ }^{37}$. Acompañando a Gori en la dirección de la revista, Ricardo del Campo se desempeñó primero como Secretario de Redacción y, luego -dejando ese lugar a Miguel Ángel Lancelotti- como Redactor en Jefe. Ambos contribuyeron de sobremanera en la publicación, ya sea a partir de artículos sueltos firmados por ellos mismos (o en nombre de La Dirección y/o La Redacción), como de secciones dedicadas a temáticas específicas.

En términos de su composición, distintos autores han referido a las características acerca del staff de la revista. Así, Scarzanella destaca que la misma "reúne los aportes de estudiosos italianos y argentinos" 38 . Por su parte, Rodríguez señala a Criminalogía Moderna como una colaboración europeo-americana, al incluir "casi a cada uno de los reconocidos abogados, criminólogos y médico legistas en Argentina y a un número de científicos europeos" ${ }^{39}$, entre los cuales sobresalían -para la autora- Lombroso y Ferri. Otro comentario al respecto es el que realiza Albornoz, quien afirma que "Gori supo agrupar a un notable staff de colaboradores que daba cuenta, entre otras cosas, de una enorme versatilidad a la hora de tejer redes relacionales en tiempo récord" ${ }^{40}$. Más allá de la apreciación personal de cada autor, la revista contaba con colaboradores locales y extranjeros. La propia revista se ocupaba de darle publicidad a los mismos, incluyendo en cada nuevo número (y más específicamente, en la tapa) la lista de todos ellos.

En lo que refiere a los colaboradores locales, quienes provenían de diversas disciplinas e instituciones, podemos mencionar entre otros a Guillermo Achával, Francisco de Veyga, Antonio Dellepiane, Luis María Drago, Victor Arreguine, Manuel Carlés, Juan Vucetich y José Ingenieros, colaborador desde junio de 1899.

Respecto a los colaboradores extranjeros, la revista contaba con profesores, abogados y catedráticos de distintas regiones del mundo, tales como Cesare Lombroso, Enrico Ferri, Pedro Figari, Charles Aldermann, Scipio Sighele, Agustín Hamon, Napoleon Colajanni, Raffaele Garofalo y Guglielmo Ferrero.

Desde noviembre de 1898 a enero de 1901 fueron editados 21 números de Criminalogía Moderna, totalizando una cantidad de seiscientos cincuenta y seis páginas. Radicada en la Ciudad de Buenos Aires ${ }^{41}$, se presentaba con periodicidad mensual, aunque ello se cumplió sobre todo en los dos primeros años de la revista, variando así la fecha de edición en los años 1900 y 1901, y dejando mucho más espacio en el intervalo entre número y número. Quizás el principal motivo de esta demora se haya debido a dificultades financieras. Al respecto, conviene destacar que la revista fundada por Pietro Gori se apoyaba en un sistema de suscripción individual, cuyas dificultades en los pagos pueden ser observadas en distintas notas publicadas en la revista ${ }^{42}$. De hecho, la falta de fondos fue, para Rodríguez, la causa principal de su desaparición hacia el año 1901.

48 En términos del acceso a la fuente, la lectura de la totalidad de sus veintiún números fue realizada a partir de tres caminos complementarios entre sí. Los números 13-14, 15, 16 y 20 fueron consultados en su formato físico en la Hemeroteca de la Biblioteca Nacional Mariano Moreno, más específicamente en la Sala de Publicaciones Periódicas Antiguas Boleslao Lewin. Los números 17-18, 19 y 21, por su parte, están incluidos en el catálogo de microfilms del Centro de Documentación e Investigación de la Cultura de Izquierdas. Finalmente, los números restantes pueden descargarse y consultarse vía 
online, ya que se encuentran -desde el año 2012-, alojados en la Biblioteca Digital de la Corte Suprema de Justicia de la Nación ${ }^{43}$.

En cuanto al detalle de su contenido, Criminalogía orientó sus artículos a temas de derecho y procedimiento penal, sociología y antropología criminal, medicina legal, legislación y jurisprudencia. Algunos de estos temas coincidían con secciones permanentes específicas, como los casos de Crónica judicial y Jurisprudencia criminal. Con el soporte de la colaboración de Juan Vucetich, se incluía una sección dedicada particularmente a la estadística policial y carcelaria, con Cuadros demostrativos y con un Resumen trimestral de estadística de la Policía de la Provincia de Buenos Aires. Otras de las secciones permanentes de la publicación eran "Notas bibliográficas" (donde se publicaban reseñas y comentarios de libros y revistas, tanto locales como internacionales), "Guía del estudiante" (una sección dedicada a reseñas bibliográficas de mayor detalle y longitud, centradas particularmente en las obras de Garofalo y Ferri) y "Colaboraciones exteriores, especiales y exclusivas" para Criminalogía Moderna, una de las secciones más relevantes en tanto observable de las contribuciones hechas por los distintos colaboradores extranjeros.

En ocasiones se agregaban otras secciones, las cuales referían a: Biografías y estudios positivos sobre las personalidades culminantes del mundo criminal, resúmenes de los procesos célebres universales y locales, juicio por jurados, necesidad de reforma de la justicia penal, pronunciaciones contra la pena de muerte $\mathrm{y}$, a partir de los apuntes del viaje de estudio emprendido por Gori y Vucetich hacia la Penitenciaría de Sierra Chica, la sección titulada "Estudios carcelarios", descripta como el puntapié inicial de una investigación carcelaria-antropológica.

51 Un último comentario que merece hacerse acerca del contenido apunta al lugar asignado a los recursos visuales, ya sea que se trate de ilustraciones, reproducciones fotográficas o litografías. En tal sentido, consultar las páginas de la revista ofrece un amplio muestrario de imágenes y maneras de retratar al homo criminalis, pero también a los autores más consagrados que allí colaboraban.

\section{Reconstruyendo las representaciones en torno a raza, inmigración y delito}

52 En el artículo que marca su inauguración, se destaca, como parte del programa de Criminalogía Moderna, estudiar "las causas profundas e infinitas que generan al delincuente o preparan socialmente las condiciones fatales a la producción del delito" ${ }^{44}$. Ahora bien, ¿cuál es el peso atribuido a la inmigración y, en ocasiones de manera interconectada, a la raza en la descripción sobre las causas de la criminalidad? En los siguientes subapartados doy a conocer las categorías que devinieron centrales tras el análisis efectuado -Teoría Fundamentada- de la publicación periódica objeto de este artículo.

\subsection{Asociación estadística entre inmigración y delincuencia}

Esta categoría fue reconstruida especialmente a partir de la lectura "Civilización y delito" de Miguel Lancelotti, artículo en el cual es planteado un panorama atravesado por distintas cuestiones criminales ${ }^{45}$. Al respecto, se hace referencia a la 
transformación en el delito (más concretamente, al pasaje -por influencia de la civilización sobre la actividad delictuosa- de una criminalidad atávica a una evolutiva), a la criminalidad de los menores (haciéndose alusión a estadísticas de diferentes países y alertando, a la vez, sobre la situación local), al considerable aumento del delito experimentado en Ciudad de Buenos Aires entre los años 1881 y 1898, y al inmenso catálogo de la "criminalidad ignorada". Por esta última, Lancelotti comprende "aquella criminalidad que no es del dominio público, que no se denuncia, ni se descubre, que escapa a toda sanción penal y que queda para siempre ignorada bajo el velo del misterio"46.

En cuanto al aumento del delito en Ciudad de Buenos Aires, este es explicado tanto por "el crecimiento considerable de la población extranjera que, en el número total de criminales contribuye con un 59 por 100 más o menos", cuanto por "el desarrollo pasmoso de la riqueza mueble y de los valores de todo género, que ha multiplicado los estímulos y las ocasiones para delinquir" ${ }^{47}$.

Al orientarnos al primero de ellos, el principal atributo o propiedad de la "asociación estadística entre inmigración y delincuencia" lo constituyen las estadísticas policiales, las cuales son evocadas con miras a corroborar el aumento de la criminalidad, que fue para el autor proporcionalmente mayor al crecimiento de la población.

Las cifras presentadas por Lancelotti procedían, al respecto, de diversas fuentes: Procedimientos del Departamento Nacional de Estadística durante el año 1886 y Censo Municipal de la Ciudad de Buenos Aires, ambas compilaciones realizadas en 1887 por Francisco Latzina, y el Anuario Estadístico de la Ciudad de Buenos Aires (1898) de Alberto Martínez. Si bien tales estadísticas eran producidas desde fuera de un ámbito consagrado académicamente ${ }^{48}$, se encontraban ligadas, en la lectura y análisis de los datos, a un determinado saber experto: la criminología en su vertiente positivista. Más concretamente, y siguiendo lo expuesto por Diego Galeano, la información estadística constituía un "campo de observación" para discutir argumentos sobre las causas de la criminalidad en la Argentina ${ }^{49}$.

De hecho, Olaeta refiere a distintos autores que apoyaron sus conceptualizaciones en estadísticas oficiales sobre la criminalidad, entre ellas especialmente las policiales, Norberto Piñero, Cornelio Moyano Gacitúa, Antonio Dellepiane, y el propio Lancelotti ${ }^{50}$.

Como fue brevemente señalado al iniciar este artículo, uno de los pilares del enfoque positivista de la criminología lo constituye el paradigma de tipo etiológico: la explicación de la criminalidad a partir del examen de las causas y factores que inciden sobre ella. Existía, por tanto, la premisa de que determinadas características hacían más propensos a los individuos a cometer actividades delictivas, una de las cuales era la nacionalidad. De tal forma, la conducta "desviada" era asociada con la procedencia extranjera.

60 Al respecto, Claudia Daniel subraya el criterio prioritario que se le daba a la nacionalidad en la construcción y presentación de estadísticas; aspecto que ilustra tanto en la producción de las cifras relativas a detenidos, como en el peso que tenía en otras publicaciones -uno de cuyos ejemplos lo constituye los anuarios estadísticos municipales- donde eran difundidos los datos elaborados por la Policía de la Capital ${ }^{51}$.

61 Como manera de darle sustento al nexo entre inmigración y delincuencia, la confluencia de saberes profanos y expertos ("estadísticos" y "criminológicos") puede ser sintetizada del siguiente modo: 
Recorriendo la historia de las estadísticas criminales en Argentina en particular, surge que, desde una mirada con pretensiones científicas, uno de los primeros focos de atención en la recopilación de datos criminológicos estaba relacionado con los inmigrantes, la delincuencia y el desorden urbano ${ }^{52}$.

No solamente la correlación lineal, planteada por Lancelotti, entre aumento del delito y crecimiento de la población extranjera, sino también la inclusión en $C M$ de Cuadros demostrativos del movimiento carcelario y de la delincuencia (así como de un Resumen trimestral de estadística de la Policía de la Provincia de Buenos Aires) pueden ser observables de la importancia atribuida a las estadísticas sobre la criminalidad desde el campo de saber criminológico.

\subsection{Racialización del nexo inmigración-delincuencia}

Esta categoría fue reconstruida, por su parte, en relación al examen realizado en torno a un detenido por homicidio; examen en el sentido de procedimiento disciplinario que habilita, siguiendo a Michel Foucault, "la constitución del individuo como objeto descriptible, analizable" ${ }^{53} \mathrm{y}$, a la vez, la de un sistema que permitiría compararlo con otros. Son señaladas así distintas aptitudes, características y rasgos -por parte de un autor que es convocado en su calidad de "especialista", Victor Mercante, director de la Escuela Normal de Mercedes- que permiten efectuar un identikit del sujeto en cuestión, el cual es apodado únicamente con la letra "D".

Llamado por el propio Mercante como el más interesante de los menores detenidos, se trata de un joven de dieciséis años nacido en Salerno, Italia. A su estudio y descripción estuvo orientado un artículo editado en el año $1900^{54}$, el cual fue modificado y ampliado posteriormente en Archivos de Criminología, Medicina Legal, Psiquiatría y Ciencias Afines, publicación dirigida por José Ingenieros entre 1902 y 1913.

Dados los intereses de investigación que dieron lugar al presente artículo, del conjunto de aspectos que fueron reseñados, la raza y la falta de adaptación constituyen los más relevantes.

Respecto al primero, se señala que, por los rasgos étnicos que presenta, "D" desciende de las razas africanas o asiáticas que poblaron un tiempo el sur de Italia. Mayor relevancia adquiere el aspecto en relación con la presunta mayor propensión de éstas al delito, debido al peso de la herencia. En los propios términos que expresa el autor, "si una raza posee mayores tendencias al crimen que otra y domina en ella el instinto criminoso, la herencia transmitirá este carácter diferencial a las generaciones sucesivas, del mismo modo que lo haría en el orden anatómico o psicológico" 55 .

Más particularmente, y apoyándose en Cesare Lombroso y Enrico Ferri -tema sobre el cual volveré cuando refiera a los saberes que estaban convocados a sustentar los vínculos entre inmigración y delincuencia-, Mercante concluye que la mayor criminalidad clasificada como "hechos de sangre" corresponde al sur de Italia, "donde dominaron fenicios, árabes, albaneses, elementos que para el delito pesan como una fatalidad" 56 .

De tal manera, el vínculo que se establece entre raza y delito es, en las más de las ocasiones, ponderado sobre los demás factores reseñados, al punto de que es concebida como "la principal causa de la naturaleza anormal de $\mathrm{D}$ " 57 , y -leído en términos del análisis efectuado mediante la Teoría Fundamentada- la propiedad más significativa de la "racialización del nexo inmigración-delincuencia"58. 
69 En otros apartados de los artículos, y con miras a explicar de manera cabal los factores que lo llevaron a "D" a la comisión del delito, Mercante complementa la influencia del "espíritu de raza" con su "falta de educación en nuestro medio social" 59 . Al respecto, el hecho de que no se haya familiarizado con los hábitos de la colectividad infantil argentina y que haya permanecido, por el contrario, completamente adaptado al lugar donde nació, permitiría asimismo explicar la comisión del homicidio ${ }^{60}$.

70 Ambos aspectos son sintetizados en la conclusión que da cierre al artículo: "Dado el espíritu de raza que en él domina sin modificaciones, la falta de hábito a las costumbres de la plebe argentina se explica cómo la fuerza de las circunstancias haya provocado la actitud enérgica del caso que se trata" ${ }^{61}$.

71 Resulta interesante señalar que las lecturas de Lancelotti y Mercante no constituyen únicamente un camino para indagar acerca de los modos en que eran tematizados los vínculos entre inmigración y delincuencia, sino también en otro de los aspectos de la cuestión criminal que tenían un fuerte protagonismo en las publicaciones de época, la criminalidad de los menores.

72 En cuanto a los saberes que eran convocados a sustentar aquellos vínculos, en el artículo de Mercante es recurrente la referencia a dos de los principales exponentes de la Scuola Positiva, en tanto cita de autoridad avalada sobre una temática en particular. Por un lado, es apuntado un argumento de matiz teórico: "Ferri nota que la distribución del delito concuerda, con la de las razas; que la gente de color posee mayores tendencias al crimen, que la blanca, y la raza latina, más que la anglosajona" ${ }^{62}$. Por el otro, para profundizar en la influencia africana y oriental en el sur de Italia, son retomadas cifras dadas a conocer por Lombroso correspondientes a homicidas (o heridores) por cada millón de habitantes: 217 para la región de la Campania, mientras que 36 para Piemonte, Liguria, Veneto y Lombardia.

De manera conjunta, ambas referencias permiten a Mercante subrayar la influencia del "espíritu de raza" en el homicidio cometido por "D". Desde otra perspectiva analítica posible, nos invita a transitar los viajes criminológicos que atravesaron distintas nociones, al ser incorporadas en un contexto geográfico distinto respecto al cual nacieron, y a la indagación de las particularidades que tienen los procesos de traducción local. Retomando la grilla de lectura que propone Sozzo acerca de las actitudes de los intelectuales locales en relación a la recepción de las ideas lombrosianas ${ }^{63}$, artículos como el de Mercante podrían ser interrogados en cuanto a su filiación con respecto a la Scuola Positiva, y por qué no, según otras corrientes de pensamiento.

74 Ya sea a partir del recurso a las estadísticas policiales (Lancelotti) o a estadísticas criminales extranjeras (Mercante), ambos artículos hasta aquí reseñados constituyen observables del peso que tiene el "lenguaje de los números" en los discursos en torno a la criminalidad ${ }^{64}$. Por su parte, lo presentado por Mercante nos ubica en un escenario de confluencia entre saberes "criminológicos" y "estadísticos", aspecto que Scarzanella sintetiza, en torno a los vínculos entre raza, inmigración y delincuencia, del siguiente modo:

Algunos criminólogos y doctores identificaron en las poblaciones de origen latino (italianos y españoles) a los responsables de haber importado al país la semilla del delito [...] La contribución que realizaron cada uno de los grupos étnicos, especialmente el italiano, a la diseminación del delito, era un tema fundamental para el análisis estadístico y los estudios criminológicos ${ }^{65}$. 
Continuando con el recorrido por las páginas de la revista, otro artículo de Lancelotti también ampliado con posterioridad, en 1910, en Archivos de Criminología, Medicina Legal, Psiquiatría y Ciencias Afines-, puede aportarnos pistas para describir una triple asociación entre alcoholismo, raza y delito ${ }^{66}$.

Allí el autor señala que "después del factor económico, quizás ningún otro adquiere tanta importancia en la producción del delito como el alcoholismo" ${ }^{67}$. Luego de recurrir a estadísticas de distintos casos nacionales (Italia, Francia, Inglaterra, Estados Unidos, Holanda y Chile) para constatar que ellas prueban que la mayor parte de los crímenes son cometidos en estado de ebriedad, afirma, para el caso de Argentina:

A falta de datos, si se tiene en cuenta que la gran masa de la población de la república se compone de argentinos, italianos y españoles en su mayor parte precisamente, los que dan las cifras más altas en las entradas a la policía por ebriedad - y que es una característica de los individuos de estas razas reñir cuando se han excedido en sus variaciones alcohólicas - otra razón por la cual la proporción de los delincuentes de estas mismas razas es mayor que la de otras ${ }^{68}$.

Se puede observar, a partir de este fragmento, el modo en que Lancelotti señala un vínculo entre el delito de riña, el alcoholismo y la composición racial mayoritaria de la población argentina, el cual marcaría una mayor proporción de delincuentes argentinos, italianos y españoles.

Si bien exento de una referencia sobre la inmigración propiamente dicha, en otro de los artículos de CM se establece un nexo entre el delito del infanticidio y las razas. Más específicamente, en uno de los "casos célebres" dados a conocer por Ricardo del Campo: los infanticidios cometidos por Marcelina Arteyas, quien dio muerte a cinco hijos suyos, sin vacilación alguna y sin ningún tipo de arrepentimiento posterior ${ }^{69}$.

Para el autor, la comisión de esta clase de delitos puede ser explicado, en general, por una pluralidad de factores. Son detallados, de esa manera, el factor hereditario, la influencia de factores sociales, la raza, la región y la cultura social. De acuerdo a los intereses de investigación que motivaron el presente artículo, me voy a detener exclusivamente en la raza. Al respecto, Del Campo afirma que "las estadísticas comparadas demuestran que el delito de infanticidio es mucho más frecuente en los pueblos de raza latina [...] El número de infanticidios es en cambio infinitamente menor entre los pueblos de origen anglo-sajón"70.

conjunto, ya sea por los vínculos entre razas, herencia y delito, como por la especificación de distintos tipos de delitos a los cuales estarían asociadas las así denominadas razas latinas (homicidio, riña e infanticidio), estas son algunas de las maneras en que fueron tematizados los nexos entre inmigración, raza y delito. Otras de ellas se circunscriben desde y en otros ámbitos geográficos. Podemos citar, al respecto, un artículo de Napoleon Colajanni en el cual cuestiona tanto la distinción entre razas inferiores y superiores, así como la influencia de la raza sobre el delito, entablando una discusión -ni más ni menos- con Lombroso y Garofalo ${ }^{71}$. Pero también es el caso de un artículo que nos sitúa en Estados Unidos, y a partir del cual reconstruí la siguiente etiqueta.

\subsection{Delincuencia de color}

1 Al plantear que la influencia de la raza se puede observar tanto en los oficios y profesiones como en la criminalidad, James Setter se pregunta si delinquen más los 
hombres de raza blanca o los de raza de color, aludiendo con ello específicamente a negros y mongoles ${ }^{72}$.

Una primera respuesta es dada en dirección de aquellas características del delincuente nato que, según una de las tesis de Lombroso, lo acercan al salvaje. Si bien el autor señala que las hipótesis lombrosianas de una retrogradación atávica han sido muy combatidas en el contexto estadounidense, puntualiza que "no puede dudarse, empero que si los dos caracteres morales fundamentales que acercan el salvaje, al delincuente son: la impulsividad y la repugnancia a todo trabajo, estas dos características se notan marcadamente en las razas de color"73. De todas maneras, conviene destacar que este argumento no es presentado de manera generalizable, sino que Setter reconoce dos excepciones a esta asociación, los negros de los estados del Sur y los chinos de California; quienes, -si bien son inferiores como raza, al tipo blanco- no pertenecen ya al tipo del "hombre salvaje".

A pesar de la existencia de estas excepciones, sostiene que "la delincuencia de color es en los Estados Unidos un hecho positivo y de fácil constatación" 74 , y ello a partir de distintas maneras: con referencia a las estadísticas criminales (pues se observa un enorme tributo de criminalidad dado por las razas de color), a las visitas realizadas a las cárceles (superabundancia de los delincuentes de color en relación con los blancos) y a la características de los delitos que cometen (delitos con un alto grado de violencia, algunos de los cuales son seguidos de homicidio).

Al orientarse sobre esta última manera de constatar la "delincuencia de color" en los Estados Unidos, el autor avanza en la dilucidación de ciertas "organizaciones criminosas" o "banda de malhechores urbanos", principalmente liderados por negros o mulatos, como las que se pueden reconstruir en un caso de complot que describe, y que -como fue señalado en la presentación de $C M$ - es acompañado por un recurso visual: el retrato de perfil del jefe de una de dichas bandas. El artículo culmina con una pregunta por las causas y el impacto (o los efectos) que esta criminalidad de color produciría en el orden social; al respecto el autor alude a un "desequilibrio moral", a un "sensible desnivel físico-moral con los otros"75.

Sintetizando el artículo de Setter -y a la vez leyéndolo en clave del análisis realizado mediante la Teoría Fundamentada-, la "delincuencia de color" se relaciona con las siguientes propiedades. Por un lado, se señalan aquellos aspectos que vinculan entre sí al salvaje y al delincuente nato, tales como la impulsividad y la repugnancia a todo trabajo. Por el otro, hay una referencia explícita a las estadísticas criminales, a la cantidad de población encarcelada y a las características de los tipos de delitos que cometen.

Como en el caso de aquellos artículos descriptos en los anteriores apartados, nos reencontramos aquí con la coincidencia de saberes estadísticos, por un lado, y criminológicos, por el otro. Para un desarrollo más cabal, sería significativo analizar la etiqueta -y en términos más amplios, los vínculos entre raza y delito- a partir de las teorías racistas presentes en la época, y de sus posibles intersecciones con los discursos criminológicos sobre el "otro".

\subsection{Bestia humana y monstruosidad fisio-psíquica}

87 Emprendiendo el viaje de vuelta a Argentina, en un artículo publicado en el año 1899, y dado a conocer desde las páginas de la revista sin ningún signo de autoría, se relatan las 
principales razones del incremento de la delincuencia. Se hace referencia así a los hechos de sangre fomentados por la concurrencia de factores cósmicos y sociales, a los atentados contra la propiedad determinados por las necesidades correspondientes al periodo final de la crisis económica, y -significativamente con respecto a mis intereses de investigación-, a "la llegada al país de ladrones conocidos expulsados por las autoridades de las naciones vecinas en la batida contra los mismos iniciada en ellas últimamente" 76 .

Este incremento se traduce en innumerables asaltos, incendios, homicidios, riñas, lesiones, robos, estafas...Del conjunto de ellos, en este breve artículo se relata el delito cometido por Saverio Patta, quien asesinó a una menor de 14 años de edad. En la dilucidación del caso, el énfasis está puesto, en continuidad con el enfoque de la revista, en el carácter del delincuente, pero también en su nacionalidad: se señala de tal manera que es napolitano, de veintidós años de edad, que vive miserablemente y hace muchos años que vino al país. En cuanto a la forma en que es clasificado al criminal, se lo considera "una bestia humana, en quien apenas si existen en embrión los sentimientos morales y facultades intelectuales" $"$.

Otros de los aspectos que permitirían definirlo como tal -y en términos de la estrategia teórico-metodológica seleccionada, otras propiedades de la etiqueta de "bestia humana "- aluden, por su parte, a su casi absoluta insensibilidad moral, a su carencia por completo de toda afectividad, a los estigmas degenerativos que presenta en su cráneo y cara y a la obtusidad que presenta su expresión.

Vemos reiterarse la centralidad de este tipo de rasgos en una de las tantas contribuciones realizadas por Ricardo del Campo a la publicación dirigida por Gori. Más concretamente, nos es presentada la figura de Amadeo Bezzi, apodado El Ñato -acusado y convicto de tentación de violación en la persona de una sordomuda-, de quien se destaca su origen italiano ${ }^{78}$. Mientras el caso en sí mismo es categorizado bajo la denominación de "monstruosidad fisio-psíquica", Bezzi es definido por el autor como "un ser doblemente monstruoso y repugnante", a la vez que como "una bestia humana enardecida por un desenfrenado instinto sexual"79.

$91 \mathrm{Al}$ ser relatados los distintos detalles del crimen, y a partir del retrato que acompaña el texto del artículo, Del Campo señala que "Amadeo Bezzi es un caso típico de monstruosidad congénita por defecto de desarrollo, en el sentido de una incompleta soldadura de las dos partes laterales del cráneo" ${ }^{10}$.

Como en otros de los artículos editados en CM, el énfasis está puesto en la descripción física de Bezzi, y más particularmente en sus rasgos "anormales", los cuales se encuentran intensamente acentuados, y permitirían comprender las causas que llevaron al delito, pero no por sí solos: a esta "monstruosidad congénita", habría que agregar otro estimulo de naturaleza ocasional.

Se comprende que un ser cuyo aspecto físico es defectuoso hasta la monstruosidad y cuyas condiciones psíquicas corresponden proporcionalmente a la morfología exterior, encuentra en ello un inconveniente insalvable para satisfacer normalmente las necesidades fisiológicas del desarrollo sexual, y se explica a la vez que en tales circunstancias haya recurrido a la violencia como único medio a su alcance de lograr aquel fin, bajo la excitación consiguiente a una prolongada y forzosa abstensión ${ }^{81}$.

93 En líneas generales, la reconstrucción de estas etiquetas no sólo constituye un camino posible para indagar en los vínculos entre inmigración europea y delincuencia, sino que 
nos invita a profundizar tanto en la centralidad puesta en la "anormalidad psicofísica del delincuente" (al ser señalados al respecto los rasgos y estigmas que presenta), cuanto en la presencia de un juicio moralista más o menos estigmatizante acerca del "otro". En suma, dos aspectos que fueron señalados por Creazzo en el capítulo respectivo dedicado a $\mathrm{CM}$, uno de los canales de difusión -al decir de la autora- del positivismo criminológico en Argentina.

Retomando, a su vez, la descripción de los saberes que permitirían sustentar los antedichos vínculos, ¿cuáles serían aquellos que están relacionados a las etiquetas de “ monstruosidad fisio-psíquica" y "bestia humana"? La descripción que realiza Sozzo de los retratos del delincuente presentes en la Revista Criminal -publicación que fue editada en 1873 desde la Ciudad de Buenos Aires, fundada y dirigida por Pedro Bourel-, nos puede aportar pistas al respecto ${ }^{82}$.

Además del hecho de compartir determinada afinidad temática con $C M$, uno de los puentes que pueden establecerse entre ambas publicaciones nos apunta a la referencia de aquellos casos criminales definidos a partir de la etiqueta de "monstruos". Así, recuperando argumentos anteriormente trabajados por Michel Foucault en Los Anormales (curso dictado en el Collège de France en el ciclo lectivo 1974-1975), el autor sostiene que algunos de los retratos del criminal fueron construidos sobre la base de una "gramática de lo monstruoso", situada en un marco de referencia "jurídico-moral":

Lo que transforma a estos 'criminales celebres' en sujetos esencial y radicalmente diferentes, monstruos, no es tanto una descripción de lo que son -como en el caso de la afirmación de una patología en clave medicalizante-, sino, paradojalmente, de lo que hacen, de sus comportamientos, de sus conductas ${ }^{83}$.

En dichos retratos también desempeña un rol central cierta mixtura con la animalidad, también observado en los dos casos reseñados en este subapartado, en torno a la definición de Bezzi y Patta como "bestias humanas", o igualmente, al ser destacada la ferocidad que rodea a cada uno de los casos en cuestión.

Otro de los elementos en común entre ambas publicaciones alude a los componentes visuales que acompañaban los retratos de los criminales. Si en $C M$ la reproducción fotográfica de Bezzi nos podía hacer testigos en primera plana de aquellos defectos físicos que habilitaban a clasificarlo como un "ser monstruoso", Sozzo señala que algunos de los criminales dados a conocer -por medio de litografías- en Revista Criminal eran "representados gráficamente para expresar que gozaban de una celebridad invertida, negativa: la 'celebridad de la monstruosidad', que traduce diferencia, distancia, deshumanización" $"$.

Para el autor, esta caracterización "antipática" de algunos delincuentes constituye una condición de posibilidad para su demonización y, por consiguiente, abre el camino al ejercicio de la violencia, el castigo, e inclusive la eliminación.

Si bien en ambas publicaciones periódicas se dibuja la figura del "otro" como un "ser diverso", el cual posee una naturaleza moral distinta a la de "nosotros", un aspecto significativo es preguntarnos cuál es el peso dado a los distintos saberes que permitirían sustentar la definición del criminal monstruoso. El propio Sozzo nos aporta una pista, al distinguir el "esencialismo moral" de Revista Criminal y el "esencialismo biológico" propio del saber criminológico positivista.

Respecto al análisis de $C M$, considero que los casos reseñados en este subapartado tienen más puntos en común con el "esencialismo moral" que con las clasificaciones expertas de la criminología positivista. Más particularmente, concibo la "gramática de 
lo monstruoso" como un saber profano, tanto porque se encuentra ligado más a un juicio moralista sobre el comportamiento del "otro" que a un conjunto de conceptos científicos o jurídicos, como por el hecho de que se trata de representaciones del delincuente que circulaban por fuera de los espacios académicamente consagrados: las descripciones eran realizadas "sobre la base de noticias extraídas de actuaciones procesales u obtenidas directamente de la crónica y se refieren a los delitos de sangre más impresionantes" ${ }^{85}$.

\section{Cerrando (provisoriamente) el telón}

A lo largo de este artículo, propuse reconstruir aquellas representaciones del delincuente, difundidas en Criminalogía Moderna, en las cuales se establecían -de manera más o menos explícita- vínculos entre raza, inmigración y delito.

El modo concreto de abordarlas fue a través de la estrategia de la Teoría Fundamentada, la cual me ha permitido no solamente producir distintas categorías que devinieron centrales en el análisis efectuado de la publicación dirigida por Pietro Gori, sino también recuperar los argumentos de Glaser y Strauss en torno a la investigación de biblioteca.

Así, por medio del relevamiento y análisis de distintos artículos, reconstruí distintas categorías (en ocasiones, etiquetas) en torno a los antedichos vínculos, tales como asociación estadística entre inmigración y delincuencia; racialización del nexo inmigración-delincuencia; delincuencia de color; bestia humana y monstruosidad fisiopsíquica.

104 En el mismo sentido, mi interés estuvo en describir cuáles eran los saberes que, ya fueren profanos o expertos, eran convocados a sustentarlos. Al respecto, hice mención a las estadísticas sobre la criminalidad (y, entre ellas, las policiales), a argumentos teóricos y estadísticos de autores vinculados a la criminología en su vertiente positivista y a la llamada "gramática de lo monstruoso".

Considero que indagar en el peso atribuido a la raza y/o a la condición inmigrante como factores criminógenos constituye un camino para describir discursos criminológicos sobre la presunta mayor tendencia a la comisión de delitos de un "otro" diferente a un "nosotros". Un recorrido que, a su vez, puede brindarnos herramientas para componer prejuicios y estereotipos sobre la imagen del delincuente del pasado. De igual manera, una incursión como la aquí realizada -que puede ser profundizada en distintas direcciones mencionadas a lo largo del artículo- es un paso más para continuar indagando en uno de los numerosos capítulos de la historia de la criminología positivista en Argentina: los modos en que eran definidos los vínculos entre inmigración y delincuencia, en un contexto de transformaciones políticas, económicas y sociales, entre otras. 


\section{Fuentes}

\section{Fuentes Publicadas}

\section{BIBLIOGRAFÍA}

Abiuso, Federico, "Inmigración y delincuencia en Buenos Aires (siglos XIX y XX): problemáticas de la criminología positivista en Argentina bajo una mirada historiográfica", Nova Criminis: Visiones criminológicas de la justicia penal, Santiago de Chile, Vol. 9, n¹3, pp. 151-177.

Anitua, Gabriel, Historias de los pensamientos criminológicos, Editores del Puerto, Buenos Aires, 2010, $590 \mathrm{p}$.

Albornoz, Martín, "Pietro Gori en la Argentina (1898-1902): anarquismo y cultura", en: Bruno, Paula (Coord.), Visitas culturales en la Argentina, 1898-1935, Biblos, Buenos Aires, 2014, pp. 23-47.

Albornoz, Martín \& Galeano, Diego, "El momento Beastly: La Policía de Buenos Aires y la expulsión de extranjeros (1896-1904)”, Astrolabio (nueva época), n¹7, pp. 6-41.

Caimari, Lila, Apenas un delincuente. Crimen, castigo y cultura en la Argentina, 1880-1955, Siglo XXI, Buenos Aires, 2004, 308 p.

Caimari, Lila, La ciudad y el crimen: delito y vida cotidiana en Buenos Aires, 1880-1940, Sudamericana, Buenos Aires, 2009, 202 p.

Caimari, Lila, "Presentación”, en Caimari, Lila (Comp.), La ley de los profanos: delito, justicia y cultura en Buenos Aires (1870-1940), Fondo de Cultura Económica, Buenos Aires, 2007, pp. 9-21.

Caimari, Lila y Sozzo, Máximo, "Introducción. Historia y cuestión criminal en América Latina: expansión, tendencias y desafíos”, en: Caimari, Lila y Sozzo, Máximo (Eds.), Historia de la cuestión criminal en América Latina, Prohistoria Ediciones, Rosario, 2017, pp. 9-27.

Castells, Florencia, "Criminalogía Moderna: saberes intelectuales y miradas finiseculares sobre crímenes y mujeres", Revista Historia y Justicia, Santiago de Chile, $\mathrm{n}^{\circ} 12,2019$. Disponible en: https://journals.openedition.org/rhj/1998 [Fecha de consulta: 6 de noviembre de 2019] Creazzo, Giudita, El positivismo criminológico italiano en la Argentina, Ediar, Buenos Aires, 2007, 259 p.

Daniel, Claudia, Un imaginario estadístico para la Argentina moderna (1869-1914), Cuadernos del Instituto de Desarrollo Social (IDES), Buenos Aires, 2009, 37 p. 
Daniel, Claudia, “Medir la moral pública. La cuantificación policial del delito en Buenos Aires, 1880-1910”, Estatística e Sociedade, México, n¹, 2011, pp. 149-165.

Devoto, Fernando, “La inmigración de masas”, en: Devoto, Fernando (Coord.), Historia de la inmigración en la Argentina, Sudamericana, Buenos Aires, 2003, pp. 247-293.

Devoto, Fernando, “La inmigración de ultramar”, en: Torrado, Susana (Comp.), Población y bienestar en la Argentina del primero al segundo Centenario, Tomo I, Edhasa, Buenos Aires, 2007, pp. 531-548.

Domenech, Eduardo, “Crónica de una 'amenaza' anunciada. Inmigración e 'ilegalidad': visiones de Estado en la Argentina contemporánea”, en: Feldman-Bianco, Bela; Rivera Sánchez, Liliana; Stefoni, Carolina \& Villa, Marta (Comps.), La construcción social del sujeto migrante en América Latina: prácticas, representaciones y categorías, FLACSO-Ecuador/CLACSO, Quito, 2011, pp. 31-77.

Ferri, Enrico, Sociología Criminal, Centro Editorial Góngora, Madrid, 1907, 353 p.

Flick, Uwe, Introducción a la investigación cualitativa, Morata, Madrid, 2012, 322 p.

Foucault, Michel, Vigilar y castigar. Nacimiento de la prisión, Siglo XXI, Buenos Aires, 2008, 359 p.

Foucault, Michel, Nacimiento de la biopolítica. Curso en el Collège de France 1978-1979, Fondo de Cultura Económica, Buenos Aires, 2012, 401 p.

Galeano, Diego, “Civilización y delito: Notas sobre cuatro criminólogos argentinos”, Revista de historia del derecho, $n^{\circ} 45,2013$, pp. 265-277.

García Fanlo, Luis, Genealogía de la argentinidad, Gran Aldea Editores, Buenos Aires, 2010, 187 p. Germani, Gino, Política y sociedad en una época de transición, Paidós, Buenos Aires, 1968, 371 p.

Germani, Gino, Estructura social de la Argentina. Análisis estadístico, Ediciones Solar, Buenos Aires, $1987,278 \mathrm{p}$.

Glaser, Barney \& Strauss, Anselm, The Discovery of Grounded Theory: strategies for qualitative research, Aldine, New Brunswick, 2008, $271 \mathrm{p}$.

Ingenieros, José, Criminología, Editorial Hemisferio, Buenos Aires, 1953, 366 p.

Lombroso, Cesare, El delito: sus causas y remedios, Ed. Victoriano Suarez, Madrid, 1902, 651 p.

Monclús Masó, Marta, La gestión penal de la inmigración. El recurso al sistema penal para el control de los flujos migratorios, Editores del Puerto, Buenos Aires, 2008, 544 p.

Olaeta, Hernán, “Surgimiento de las estadísticas criminales en Argentina. La influencia de los discursos criminológicos en la producción y análisis de datos de la Ciudad de Buenos Aires (1885-1921)", Delito y Sociedad, Buenos Aires/Santa Fe, Vol. 24, nº40, 2015, pp. 31-62.

Olaeta, Hernán, La construcción científica de la delincuencia. El surgimiento de las estadísticas criminales en la Argentina, Universidad Nacional de Quilmes, Bernal, 2018, 74 p.

Pasquino, Pasquale, "Criminology: The Birth of a Special Knowledge". En: Burchell, Graham; Gordon, Colin \& Miller, Peter (Eds.), The Foucault Effect. Studies in Governmentality, The University of Chicago Press, Chicago, 1991, pp. 235-251.

Rodríguez, Julia, Civilizing Argentina. Science, Medicine and the Modern State, University of North Carolina Press, Chapel Hill, 2006, 306 p.

Rodríguez Morales, Teresita, "La Revista de Policía de Buenos Aires: ¿inauguración de un género periodístico moderno? (1897-1909)”, Revista Historia y Justicia, Santiago de Chile, n¹2, 2019. 
Disponible en: https://journals.openedition.org/rhj/1961 [Fecha de consulta: 6 de noviembre de 2019]

Rotondo, Francesco, Itinerari alla periferia di Lombroso. Pietro Gori e la 'Criminalogía moderna' in Argentina, Napoli, Editoriale Scientifica, 2014, 195 p.

Ruibal, Beatriz, Ideología del control social. Buenos Aires 1880-1920, Centro Editor de América Latina, Buenos Aires, 1993, 81 p.

Salvatore, Ricardo, "Penitentiaries, Visions of Class, and Export Economies: Brazil and Argentina Compared", en: Salvatore, Ricardo \& Aguirre, Carlos (Eds.), The Birth of the Penitentiary in Latin America: Essays on Criminology, Prison Reform, and Social Control, 1830-1940, University of Texas Press, Austin, 1996, pp. 194-223.

Salvatore, Ricardo, “Criminología positivista, reforma de prisiones y la cuestión social/obrera en Argentina”, en: Suriano, Juan (Ed.), La cuestión social en Argentina, 1870-1943, Editorial La Colmena, Buenos Aires, 2000, pp. 127-159.

Scarzanella, Eugenia, “Sanos, Honestos y Latinos: Los italianos y la selectividad en la política inmigratoria en argentina entre 1890 Y 1955”, Horizontes y Convergencias, 2009, p. 1-13. Disponible en: http://horizontesyc.com.ar/?p=3594 [Fecha de consulta: 6 de noviembre de 2019]

Scarzanella, Eugenia, Ni gringos ni indios. Inmigración, criminalidad y racismo en la Argentina, 1890-1940, Universidad de Quilmes, Bernal, 2015, 172 p.

Sozzo, Máximo, "Tradutore traditore. Traducción, importación cultural e historia del presente de la criminología en América Latina", en: Sozzo, Máximo (Coord.), Reconstruyendo las criminologías críticas, Ad-Hoc, Buenos Aires, 2006, pp. 353-431.

Sozzo, Máximo, “Retratando al 'homo criminalis': esencialismo y diferencia en las representaciones 'profanas' del delincuente en la Revista Criminal (Buenos Aires, 1873)", en Caimari, Lila (Ed.), La ley de los profanos: delito, justicia y cultura en Buenos Aires (1870-1940), Fondo de Cultura Económica, Buenos Aires, 2007, pp. 23-65.

Sozzo, Máximo, "Pintando con números. Fuentes estadísticas de conocimiento y gobierno de la cuestión criminal”, en: Inseguridad, prevención y policía, FLACSO Ecuador, Quito, 2008, pp. 21-65.

Sozzo, Máximo, “Los exóticos del crimen. Inmigración, delito y criminología positivista en la Argentina (1887-1914)”, Delito y Sociedad, Buenos Aires/Santa Fe, Vol. 19, n³2, 2011, pp. 19-51.

Sozzo, Máximo. "Los usos de Lombroso. Tres variantes en el nacimiento de la criminología positivista en Argentina”, en: Caimari, Lila \& Sozzo, Máximo (Eds.), Historia de la Cuestión Criminal en América Latina, Prohistoria Ediciones, Rosario, 2017, pp. 28-69.

Valles, Miguel, Técnicas cualitativas de investigación social. Reflexión metodológica y práctica profesional, Síntesis, Madrid, 1997, 430 p.

\section{NOTAS}

1. Foucault, Michel, Nacimiento de la biopolítica. Curso en el Collège de France, 1978-1979, Fondo de Cultura Económica, Buenos Aires, 2012.

2. Pasquino, Pasquale, "Criminology: The Birth of a Special Knowledge", en: Burchell, Graham; Gordon, Colin \& Miller, Peter (Eds.). The Foucault Effect. Studies in governmentality, The University of Chicago Press, Chicago, 1991. 
3. Para un mayor detalle de estas clasificaciones remito a las lecturas de Lombroso, Cesare, El delito: sus causas y remedios, Ed. Victoriano Suarez, Madrid, 1902; Ferri, Enrico, Sociología Criminal, Centro Editorial Góngora, Madrid, 1907.

4. Ver Ingenieros, José, Criminología, Editorial Hemisferio, Buenos Aires, 1953. Dada la centralidad de su clasificación, no resulta para nada azaroso que una de las traducciones del libro en italiano haya sido Nuova classificazione dei delincuenti.

5. Ingenieros, José, "Criterios generales que orientarán el estudio de los locos delincuentes", Criminalogía Moderna, Buenos Aires, Vol. III, n¹6, 1900, pp. 486-495.

6. Sozzo, Máximo, "Los exóticos del crimen. Inmigración, delito y criminología positivista en la Argentina (1887-1914)", Delito y Sociedad, Buenos Aires/Santa Fe, Vol. 19, n³2, 2011, p. 27.

7. Creazzo, Giudita, El positivismo criminológico italiano en la Argentina, Ediar, Buenos Aires, 2007, p. 97.

8. Castells, Florencia, "Criminalogía Moderna: saberes intelectuales y miradas finiseculares sobre crímenes y mujeres”, Revista Historia y Justicia, Santiago de Chile, n¹2, 2019.

9. Acerca de la distinción entre saberes profanos y expertos, los primeros serían aquellos que circulan por fuera de los espacios consagrados (académicos, científicos, jurídicos) en los que se diseña la ley y se dan a conocer las doctrinas jurídicas o científicas que la sustentan; aquellos que se encuentran en condición de exterioridad respecto a los circuitos institucionales en los que se define qué es un delito, quién es el transgresor y cuál sería la naturaleza del mejor castigo. En oposición, los saberes expertos refieren a los conceptos científicos y jurídicos y a los conocimientos especializados que pertenecen a ámbitos o espacios consagrados, sea en el plano académico como también en el institucional. Ver: Caimari, Lila. "Presentación”, en: Caimari, Lila (Comp.), La ley de los profanos: delito, justicia y cultura en Buenos Aires (1870-1940), Fondo de Cultura Económica, Buenos Aires, 2007, pp. 9-21.

10. Monclús Masó, Marta. La gestión penal de la inmigración. El recurso al sistema penal para el control de los flujos migratorios. Editores del Puerto, Buenos Aires, 2008, p. 42.

11. Glaser, Barney \& Strauss, Anselm, The Discovery of Grounded Theory: Strategies for Qualitative Research, Aldine, New Brunswick, 2008. Especialmente, sobre método de comparación constante, ver capitulo V.

12. Hago la aclaración de que, siguiendo lo expuesto por Glaser y Strauss, las categorías pueden ser de dos clases, aquellas que el investigador construyó él mismo y las que fueron abstraídas del lenguaje de la situación de investigación, las cuales son definidas como etiquetas.

Otros autores conceptualizan a las categorías tomadas o derivadas directamente del lenguaje usado por los sujetos estudiados como códigos en vivo. Ver, a modo de ejemplo, Flick, Uwe, Introducción a la investigación cualitativa, Morata, Madrid, 2012.

13. Valles, Miguel, Técnicas cualitativas de investigación social. Reflexión metodológica y práctica profesional, Síntesis, Madrid, 1997.

14. Para mayor detalle, remito a Glaser, B. \& Strauss, A., The Discovery, Op. Cit., especialmente el capítulo VII, "New Sources for Qualitative Data".

15. Caimari, Lila \& Sozzo, Máximo, "Introducción. Historia y cuestión criminal en América Latina: expansión, tendencias y desafíos”, en: Caimari, Lila y Sozzo, Máximo (Eds.), Historia de la cuestión criminal en América Latina, Prohistoria Ediciones, Rosario, 2017.

16. Germani, Gino, Política y sociedad en una época de transición, Paidós, Buenos Aires, 1968.

17. Germani, Gino, Estructura social de la Argentina. Análisis estadístico, Ediciones Solar, Buenos Aires, 1987.

18. Devoto, Fernando, "La inmigración de ultramar", en: Torrado, Susana (Comp.), Población y bienestar en la Argentina del primero al segundo Centenario, Tomo I, Edhasa, Buenos Aires, 2007, p. 536.

19. Anitua, Gabriel. Historias de los pensamientos criminológicos, Editores del Puerto, Buenos Aires, 2010, p. 205. 
20. Caimari, Lila, La ciudad y el crimen: delito y vida cotidiana en Buenos Aires, 1880-1940, Sudamericana, Buenos Aires, 2009.

21. Domenech, Eduardo. “Crónica de una 'amenaza' anunciada. Inmigración e 'ilegalidad': visiones de Estado en la Argentina contemporánea”, en: Feldman-Bianco, Bela; Rivera Sánchez, Liliana; Stefoni, Carolina \& Villa, Marta (Comps.), La construcción social del sujeto migrante en América Latina: prácticas, representaciones y categorías, FLACSO-Ecuador/CLACSO, Quito, 2011.

22. Ver Albornoz, Martín \& Galeano, Diego, "El momento Beastly: La Policía de Buenos Aires y la expulsión de extranjeros (1896-1904)”, Astrolabio (nueva época), n¹7, pp. 6-41. Galeano, Diego, Delincuentes viajeros. Estafadores, punguistas y policías en el Atlántico sudamericano, Siglo XXI, Buenos Aires, 2018.

23. García Fanlo, Luis, Genealogía de la argentinidad, Gran Aldea Editores, Buenos Aires, 2010, p. 17.

24. Ruibal, Beatriz, Ideología del control social. Buenos Aires, 1880-1920, Centro Editor de América Latina, Buenos Aires, 1993.

25. Salvatore, Ricardo, "Penitentiaries, Visions of Class, and Export Economies: Brazil and Argentina Compared", en: Salvatore, Ricardo \& Aguirre, Carlos (Eds.), The Birth of the Penitentiary in Latin America: Essays on Criminology, Prison Reform, and Social Control, 1830-1940, University of Texas Press, Austin, 1996.

26. Salvatore, Ricardo, “Criminología positivista, reforma de prisiones y la cuestión social/obrera en Argentina”, en: Suriano, Juan (Ed.), La cuestión social en Argentina, 1870-1943, Editorial La Colmena, Buenos Aires, 2000.

27. Scarzanella, Eugenia, Ni gringos ni indios. Inmigración, criminalidad y racismo en la Argentina, 1890-1940, Universidad Nacional de Quilmes, Bernal, 2015.

28. Caimari, Lila, Apenas un delincuente: crimen, castigo y cultura en la Argentina, 1880-1955, Siglo XXI, Buenos Aires, 2004.

29. Sozzo, Máximo, "Los exóticos del crimen. Inmigración, delito y criminología positivista en la Argentina (1887-1914)", Delito y Sociedad, Vol. 19, n³2, 2011.

30. En tal sentido, en otro texto suyo cuyo eje es unir la problemática de la traducción y de la criminología - tanto en el pasado como en el presente-, el autor destaca que "los vocabularios criminológicos traducidos/importados no se mantuvieron intocados, sino que el 'viaje cultural' entre el allá y el acá -a través de las traducciones y la utilización de lo traducido- les hacía adquirir nuevas formas, los metamorfoseaba. Pero los rasgos o caracteres novedosos no implicaron la destrucción total de una matriz discursiva mínima común (positivismo criminológico)". Sozzo, Máximo, "Tradutore, traditore. Traducción, importación cultural e historia del presente de la criminología en América Latina", en: Sozzo, Máximo (Coord.), Reconstruyendo las criminologías criticas, Ad-Hoc, Buenos Aires, 2006, p. 382.

31. Sozzo, M., "Los exóticos", Op. Cit., p. 29.

32. Para mayor detalle acerca de las mismas, remito a Abiuso, Federico, "Inmigración y delincuencia en Buenos Aires (siglos XIX y XX): problemáticas de la criminología positivista en Argentina bajo una mirada historiográfica", Nova Criminis. Visiones criminológicas de la justicia penal, Santiago de Chile, Vol. 9, $\mathrm{n}^{\circ} 13$, pp. 151-177.

33. Al respecto, menciono alguno de los temas: "Escuela Positiva, su método"; "Doctrina clásica y doctrina positiva"; "Clasificación de los delincuentes y de las causas de la delincuencia (causas antropológicas, físicas y sociales)"; "Utilidad práctica de la clasificación y del conocimiento de los delincuentes" y “Teoría de los sustitutivos penales de Ferri”. Para más detalle del programa, ver Creazzo, G., El positivismo criminológico, Op. Cit., p. 41.

34. Respecto de este anclaje institucional, Ingenieros señala que "la Escuela Positiva ha visto su obra coronada por una larga serie de triunfos, en Congresos, en polémicas, en la vida judicial y, por fin, en las mismas Universidades oficiales", aludiendo particularmente a la cátedra de Medicina Legal de la Universidad de Buenos Aires y a la labor de Francisco de Veyga a su cargo, 
definido su desempeño como "una conquista de la enseñanza oficial por las ideas positivas". Ingenieros, José, "La escuela positiva en nuestra enseñanza universitaria", Criminalogía Moderna, Buenos Aires, Vol. 3, n²0, 1900, pp. 616-617.

35. Olaeta, Hernán, La construcción científica de la delincuencia. El surgimiento de las estadísticas criminales en la Argentina, Universidad Nacional de Quilmes, Bernal, 2018, p. 16.

36. Rodríguez, Julia, Civilizing Argentina. Science, Medicine and the Modern State, University of North Carolina Press, Chapel Hill, 2006.

37. Albornoz, Martín, "Pietro Gori en la Argentina (1898-1902): anarquismo y cultura", en: Bruno, Paula (Coord.), Visitas culturales en la Argentina, 1898-1935, Biblos, Buenos Aires, pp. 23-47. Para otro ejemplo de esta caracterización, ver Rotondo, Francesco, Itinerari alla periferia di Lombroso. Pietro Gori e la 'Criminalogía moderna' in Argentina, Napoli, Editoriale Scientifica, 2014.

38. Scarzanella, E., Ni gringos, Op. Cit., p. 18.

39. Rodríguez, J., Civilizing Argentina, Op. Cit., p. 47 (traducción propia).

40. Albornoz, M., "Pietro Gori”, Op. Cit., p. 33.

41. La capital y ciudad más poblada de Argentina está situada en la región centro-este del país, sobre la orilla sur del Río de la Plata, en la región pampeana. Se encuentra dividida en 15 comunas que agrupan a 48 barrios. Tiene sus propios poderes ejecutivo, legislativo y judicial. Desde 1880 hasta el presente, se la llama también Capital Federal.

42. A modo de ejemplo: "Mas como nosotros queremos progresar continuamente aumentando en todos sentidos la importancia y el interés de esta publicación, advertimos que, desde hoy, la Administración será inexorable con todos aquellos que no correspondan como deben, abonando los números que ya han recibido y los que se continúen mandando. 'Criminalogía Moderna' ha superado ya triunfalmente su 1er. semestre de vida con progresos y mejoras continuas y estamos seguros que, si todos los suscritores cumplen con su deber, nuestra publicación mejorará continuamente". La Administración, "A nuestros A nuestros Agentes, Suscriptores y Lectores. IMPORTANTE”, Criminalogía Moderna, Buenos Aires, Vol. 2, n6, 1899, p. 193.

43. Para mayor información del proceso de digitalización, remito a la siguiente noticia del Centro de Información Judicial: http://www.cij.gov.ar/nota-9173-La-Biblioteca-Digital-de-la-Corteincorpor--la-primera-revista-de-criminolog-a-argentina.html. Por su parte, la descarga de los números disponibles fue realizada desde el siguiente sitio web: https:// bibliotecadigital.csjn.gov.ar/revistas/

44. La Redacción, “¡Guerra al delito!”, Criminalogía Moderna, Buenos Aires, Vol. 1, n¹, 1898, p. 1. 45. Lancelotti, Miguel, "Civilización y delito", Criminalogía Moderna, Buenos Aires, Vol. 2, $\mathrm{n}^{\circ} 13-14,1899$, p. 406-413.

El hecho de que sea republicado con posteridad en Revista de Policía -entre los meses de septiembre y octubre de 1904- constituye indudablemente un aspecto interesante para indagar en los intercambios acaecidos entre dicha publicación y las revistas especializadas de la misma época. Ver al respecto: Rodríguez Morales, Teresita, "La Revista de Policía de Buenos Aires: ¿inauguración de un género periodístico moderno? (1897-1909)", Revista Historia y Justicia, Santiago de Chile, ${ }^{\circ} 12,2019$.

46. Lancelotti, M., “Civilización”, Op. Cit., p. 412.

47. Lancelotti, M., “Civilización”, Op. Cit., p. 411.

48. Si bien este rasgo permite conceptualizarlas como saberes profanos, de todos modos, es significativo mencionar que ya en el siglo XIX los policías le adjudican una cierta "profesionalidad" a la elaboración de estadísticas.

49. Galeano, Diego, "Civilización y delito: Notas sobre cuatro criminólogos argentinos", Revista de historia del derecho, $\mathrm{n}^{\circ} 45,2013$, p. 265-277.

50. Olaeta, Hernán, "Surgimiento de las estadísticas criminales en Argentina. La influencia de los discursos criminológicos en la producción y análisis de datos de la Ciudad de Buenos Aires (1885-1921)", Delito y Sociedad, Buenos Aires/Santa Fe, Vol. 24, n40, 2015, pp. 31-62. 
51. Daniel, Claudia, Un imaginario estadístico para la Argentina moderna (1869-1914), Cuadernos del IDES, Buenos Aires, 2009; Daniel, Claudia, "Medir la moral pública. La cuantificación policial del delito en Buenos Aires, 1880-1910”, Estatística e Sociedade, México, n¹, 2011, pp. 149-165.

52. Olaeta, H., La construcción, Op. Cit., p. 63.

53. Foucault, Michel, Vigilar y castigar. Nacimiento de la prisión, Siglo XXI, Buenos Aires, 2008, p. 221.

54. Mercante, Victor, "El detenido D. bajo el punto de vista de su educación. Sociología criminal", Criminalogía Moderna, Buenos Aires, Vol. 3, n¹9, 1900, pp. 587-592.

55. Mercante, V., "El detenido D”, Op. Cit., p. 588.

56. Mercante, V., "El detenido D”, Op. Cit., p. 588.

57. Mercante, V., “El detenido D”, Op. Cit., p. 588.

58. Hago la aclaración de que, al referirme a la raza (o a la "racialización"), no pretendo hacer eco de significado biológico alguno ni tampoco establecer un sistema clasificatorio, más bien aludo a cómo se representa la diversidad étnica en los discursos que se construyen sobre el "otro".

59. Mercante, V., "El detenido D”, Op. Cit., p. 589.

60. Sería interesante leer esta "falta de adaptación" a la luz de distintos aspectos señalados en Devoto, Fernando, "La inmigración de masas", en Historia de la inmigración en la Argentina, Sudamericana, Buenos Aires, 2003, p. 247-293.

61. Mercante, V., “El detenido D”, Op. Cit., p. 592.

62. Mercante, V., “El detenido D”, Op. Cit., p. 588.

63. Sozzo, Máximo, "Los usos de Lombroso. Tres variantes en el nacimiento de la criminología positivista en Argentina", en: Caimari, Lila \& Sozzo, Máximo (Eds.), Historia de la Cuestión Criminal en América Latina, Prohistoria Ediciones, Rosario, 2017.

64. Sozzo, Máximo, Inseguridad, prevención y policía, FLACSO Ecuador/CLACSO, Quito, 2008, p. 29.

65. Scarzanella, Eugenia, "Sanos, honestos y latinos: los italianos y la selectividad en la política inmigratoria en argentina entre 1890 y 1955", Horizontes y Convergencias, 2009, p. 1-2.

66. Lancelotti, Miguel, "Alcoholismo y delito", Criminalogía Moderna, Buenos Aires, Vol. 3, n¹7-18, 1900, pp. 529-534.

67. Lancelotti, M., “Alcoholismo”, Op. Cit., p. 529.

68. Lancelotti, M., “Alcoholismo”, Op. Cit., p. 530.

69. Del Campo, Ricardo, "Madres criminales. Los infanticidios de La Magdalena”, Criminalogía Moderna, Buenos Aires, Vol. 2, n9, 1899, pp. 277-279.

70. Del Campo, R., "Madres criminales", Op. Cit., p. 278.

71. Colajanni, Napoleon, “Raza y Delito”, Criminalogía Moderna, Buenos Aires, Vol. 2, n¹2, 1899, pp. 350-353.

72. Setter, James, "La delincuencia de color en los Estados Unidos de N.A", Criminalogía Moderna, Buenos Aires, Vol. 2, n7, 1899, pp. 203-205.

73. Setter, J., "La delincuencia", Op. Cit., pp. 203-204.

74. Setter, J., "La delincuencia”, Op. Cit., p. 204.

75. Setter, J., "La delincuencia”, Op. Cit., p. 205.

76. Anónimo, "Policía”, Criminalogía Moderna, Buenos Aires, Vol. 2, n4, 1899, p. 110.

77. Anónimo, "Policía", Op. Cit.

78. Del Campo, Ricardo, "La monstruosidad en la delincuencia", Criminalogía Moderna, Buenos Aires, Vol. 2, n¹0, 1899, pp. 292-293.

79. Del Campo, R., “La monstruosidad”, Op. Cit., p. 292.

80. Del Campo, R., "La monstruosidad”, Op. Cit., p. 293.

81. Del Campo, R., "La monstruosidad”, Op. Cit., p. 293.

82. Sozzo, Máximo, "Retratando al 'homo criminalis': esencialismo y diferencia en las representaciones 'profanas' del delincuente en la Revista Criminal (Buenos Aires, 1873)”, en: 
Caimari, Lila (Ed.), La ley de los profanos: delito, justicia y cultura en Buenos Aires (1870-1940), Fondo de Cultura Económica, Buenos Aires, 2007.

83. Sozzo, M., "Retratando", Op. Cit., p. 56.

84. Sozzo, M., "Retratando", Op. Cit., p. 57.

85. Creazzo, G., El positivismo criminológico, Op. Cit., p. 41.

\section{RESÚMENES}

En este artículo propongo reconstruir aquellas representaciones del delincuente producidas en Criminalogía Moderna, revista dirigida por Pietro Gori y editada desde Buenos Aires entre 1898 y 1901. A partir de la Teoría Fundamentada como metodología de investigación, propongo diversas categorías surgidas tras haber aplicado los procedimientos del método de comparación constante sobre los 21 números de la revista. Al efectuar este recorrido he pretendido contribuir a la indagación de los modos en que la criminología positivista definió las relaciones entre inmigración y delincuencia, así como componer prejuicios y estereotipos del delincuente del pasado.

Dans cet article, je propose de reconstituer les représentations du délinquant produites dans Criminalogía Moderna, une revue dirigée par Pietro Gori et éditée à Buenos Aires entre 1898 et 1901. Basé sur la Théorie ancrée comme méthodologie de recherche, je propose plusieurs catégories apparues après avoir appliqué les procédures de la méthode de la comparaison constante sur les 21 numéros de la revue. Ce faisant, j'ai cherché à contribuer à l'étude de la façon dont la criminologie positiviste a défini les relations entre l'immigration et la délinquance, ainsi qu'à composer des préjugés et des stéréotypes sur les délinquants du passé.

In this article I propose to reconstruct those representations of the offender produced in Criminalogía Moderna, a journal directed by Pietro Gori and edited from Buenos Aires between 1898 and 1901. Based on the Grounded Theory as a research methodology, I propose various categories, as a producto of having applied the procedures of the Constant comparison method on the 21 issues of the journal. In making this itinerary, I have tried to contribute to the investigation of the ways in which positivist criminology defined the relations between immigration and crime, as well as composing prejudices and stereotypes of the offender of the past.

\section{ÍNDICE}

Palabras claves: criminología positivista, teoría Fundamentada, representaciones del delincuente, Buenos Aires, siglos XIX y XX

Mots-clés: criminologie positiviste, théorie ancrée, délinquance, représentations, Buenos Aires, XIX-XX siècles

Keywords: Buenos Aires, nineteenth and twentieth centuries, positivist criminology, grounded theory, representations 


\section{AUTOR}

\section{FEDERICO LUIS ABIUSO}

Docente de la carrera de Sociología y doctorando en Ciencias Sociales por la Universidad de Buenos Aires, Argentina. Este trabajo forma parte de mi proyecto de tesis doctoral, titulada "Feos, sucios y malos. Un análisis comparativo de imaginarios estatales pasados y presentes acerca de las relaciones entre inmigración y delincuencia en el ámbito de la ciudad de Buenos Aires", codirigida por Néstor Cohen y Máximo Sozzo. La investigación se ha desarrollado en el marco de los siguientes proyectos UBACyT, con sede en el Instituto de Investigaciones Gino Germani: "La interseccionalidad entre la etnia y el género desde la perspectiva de las clases sociales, en población migrante residente en el AMBA", dirigido por Gabriela Gómez Rojas; "Diversidad etno-nacional y construcción de desigualdades en la institución escolar y judicial. Un abordaje teórico metodológico en el abordaje de los casos del AMBA y la Provincia de Mendoza"; y "Los puentes entre el poder judicial, la institución educativa y la sociedad civil ante la diversidad etno-nacional en el AMBA", dirigidos por Néstor Cohen. Correo electrónico: abiusofederico[at]yahoo.com.ar 